\title{
CRITERIA FOR SELECTING AEROSOL PACKAGING AND DETERMINING THE OPTIMUM QUANTITY OF A PROPELLANT
}

\author{
Bogdan Putyatin \\ Department of Quality, Standardization and Audit \\ Limited Liability Company Production and Trading Firm "Farmakom" \\ 17 Yurievskaya str., Kharkiv, Ukraine, 61001 \\ putyatinb@gmail.com
}

Ekaterina Kunitsia

Department of Innovative Food and Restaurant Technologies

Kharkiv Institute of Trade and Economics of Kyiv National University of Trade and Economics

8 O. Yarosh lane, Kharkiv, Ukraine, 61045

ekaterina.kunitsia@gmail.com

Natalia Sytnik

Department of studies of technology for processing oils and fats

Ukrainian Scientific Research Institute of Oils and Fats of the National Academy of Agricultural

Sciences of Ukraine

2a Dziuba ave., Kharkiv, Ukraine, 61019

ntlsytnik@gmail.com

\begin{abstract}
Development of a new generation of functional antiage cosmetics is a most important area of cosmetic industry development. An integral part of such products are biologically active substances (BAS) with essential oils, being among the sources of which.

Each essential oil is characterized by a well balanced unique composition of biologically active substances.

Development of new cosmetic products consists of correct selection of the required composition of components with required properties and selection of a suitable package, preserving product properties throughout its shelf life.

During production of cosmetic products in aerosol package a number of issues are solved, unlike with antiage-products in form of creams in customary tubes. The degree of oxidation-reduction reactions, having negative impact on the properties of essential oils, is substantially reduced.

The concentration providing for the optimum degree of evacuation and excess pressure in the packaging are essential issues.

The aim of this research is to determine the degree of evacuation of the contents, excess pressure, and mass fraction of a propellant in the product test samples to find the samples of aerosol package with optimum parameters.

A number of tests to determine the degree of evacuation of the contents from aerosol package, excess pressure and a mass fraction of a propellant have been performed. The greatest degree of evacuation of products was observed with mass fraction of propellant of $13.79 \%$. Based on the results of the tests for excess pressure in aerosol packaging, it has been found, that with mass fraction of a propellant of $13.79 \%$ excess pressure is $0.4 \mathrm{MPa}$, which was taken as an optimum value. The test showed that the mass of a propellant of $16 \mathrm{~g}$ evacuates the product from aerosol package to the maximum extent and does not exceed the acceptable limits for excess pressure $(0.2-0.6 \mathrm{MPa})$.
\end{abstract}

Keywords: aerosol packaging, propellant, degree of evacuation, excess pressure, cosmetic product GYDERLIFEINTENSIVE.

DOI: $10.21303 / 2504-5695.2020 .001374$

\section{Introduction}

One of the most important issues during the development of any cosmetic product is the selection of correct package $[1,2]$. It is not enough to manufacture a product of high quality; an important and a critical moment is the selection of a package for a cosmetic product. Surely, the package of perfumery and cosmetics must be attractive, as this is the first thing the consumer sees; but its functional selection is still a determining factor. Correctly selected package of a cosmetic product accounts for its functionality throughout the shelf life and for preservation of its claimed properties [1-3]. 
If a packaging is selected incorrectly, various physicochemical processes can occur in the product during its storage, transportation and use, leading to deterioration of its consumptive qualities, quality impairment. Invariability of odour, colour and functional properties throughout the labelled shelf life is a most important parameter of the reliability of a package selected [3, 4].

Special attention should be paid to the issues of packaging for cosmetic products, containing natural essential oils. Natural essential oils are highly volatile oily liquids, obtained from plant raw materials. They are called essential because of their volatility. Light, air, humidity change the structure of essential oils; oxidation, gumming reactions occur, affecting physical and therapeutic qualities of the natural product. This is why the cosmetic products, containing essential, oils should be kept away from the above external factors.

With a glance to these factors one of the most suitable types of package for such cosmetic products is aerosol package. A propellant, used in aerosol package, does it brilliantly by displacing oxygen, which is a potent oxidant. With a glance to the specificity of aerosol package a number of demands are posed to it. The demands to perfumery and cosmetics in aerosol packaging are laid down in the international standard ISO 22715:2006 Cosmetics -Packaging and labelling [5].

The degree of evacuation of contents from aerosol packaging is a key demand to this type of product. Correct selection of the quantity of a propellant is of great importance for maximum evacuation of the product. Taking previously developed cosmetic product GYDERLIFE-INTENSIVE [6] as an example, it is proposed to use 1,1,2,2-tetrafluoroethane (Freon-134a). The advantages of this propellant gas are the required safety criteria: non-toxicity, non-flammability, ODP coefficient (ozone depletion potential), equaling to zero [7, 8].

The main parameters, affecting quality of a cosmetic product, are the degree of evacuation of the contents from aerosol package, excess pressure, mass fraction of a propellant in the test product $[3,4]$. To determine the most effective amount of a propellant, which is necessary for evacuation of the cosmetic product GYDERLIFE-INTENSIVE in form of spray, a number of tests on ten model samples were carried out.

Therefore, the aim of this research is to determine the degree of evacuation of the contents, excess pressure, and mass fraction of a propellant in the test samples to determine the samples of aerosol package with optimum parameters.

The task of the research is to study control samples of aerosol packages, to determine the degree of evacuation for each sample with the use of difference in weights of the full container and that of the container after it contents has been discharged, excess pressure, mass fraction of a propellant.

\section{Materials and methods}

\section{1. Test materials and equipment used in the experiment}

The following equipment and materials were used in one research $[3,4,7]$ :

- laboratory scale with the greatest weighing range of $500 \mathrm{~g}$ and weighing error not more than $\pm 0.03 \mathrm{~g}$;

- special spray nozzle with an injection needle;

- $50 \mathrm{~mL}$ graduated cylinder - under GOST 1770;

- stopwatch with the least count of $0.20 \mathrm{sec}$ - under TU 25-1819.002;

- 500 mL flask KH-1-500-29/32 TC - under GOST 25336;

- glass rod;

- octyl or butyl alcohol - under GOST 5208;

- propellant Freon -134a;

- $175 \mathrm{~mL}$ aluminium bottles/(Manufacturer MATRAMETAL, Hungary);

- valves and sprayers (manufacturer KOH-I-NOOR, Czech Republic);

- cosmetic product GYDERLIFE-INTENSIVE [9].

\section{2. Method for determination of the degree of evacuation of the contents of aerosol} packaging

The test is carried out for continuous release aerosols and sprays [3, 4, 9]. Weight the container together with the sprayer or a tip to within $0.01 \mathrm{~g}\left(m_{4}\right)$. Then operate the valve or the 
tip to remove the whole material and re-weight the container with the sprayer of tip again to within $0.01 \mathrm{~g}\left(m_{5}\right)$.

Calculate the contents discharge in per cent $(X)$ using the equation:

$$
X=\frac{m_{4}-m_{5}}{m_{6}} \times 100
$$

where $m_{6}$ - weight of the labelled contents, $g$ (or obtained by multiplying the nominal volume by the density of the preparation).

Unless otherwise stated in the pharmacopoeial article or regulatory documents, the contents discharge percentage must be not less than $90 \%$, and the result is the arithmetic mean, obtained from determination of the discharge of the contents of 3 containers in per cent.

\section{3. Method of determination of excess pressure in aerosol packaging}

Allow the packages to stand at a room temperature for 1 hour and measure the pressure inside the package using the manometer (accuracy class 2.5 ). The pressure must comply with the requirements of the pharmacopoeial article or regulatory documents and to be 0.2 to $0.6 \mathrm{MPa}$ $\left(2-6 \mathrm{kgf} / \mathrm{cm}^{2}\right)[3,4,7]$.

\section{4. Method for determination of mass fraction of a propellant}

Test procedure: place a glass rode into a flask, introduce $50 \mathrm{~mL}$ of octyl alcohol and rinse the walls of the flask with it. Weight the flask with the material and the glass rod. After removing a tip allow the full aerosol packaging to stand at the ambient temperature for at least $30 \mathrm{~min}$ and weight it together with a special sprayer nozzle. Shake the packaging thoroughly for 20-30 s and discharge the whole material into the conic flask in small portions, shaking the bottle from time to time as foam in the flask disappears. To accelerate disappearance of the foam mix the contents of the flask with the glass rod until the foam disappears completely. If the flask with the contents is significantly cooled down, heat to the room temperature and weight $[3,4,7]$.

Calculate the mass fraction of the propellant $P_{2}$ using the equation:

$$
P_{2}=\frac{m-m_{1}}{m-m_{2}} \times 100
$$

where $m$ - weight of aerosol package with contents, $\mathrm{g} ; m_{1}$ - mass of aerosol package with residue after discharging the contents, $g ; m_{2}$ - mass of empty aerosol package, $\mathrm{g}$.

3. Results of determination of the degree of evacuation of the contents, excess pressure, mass fraction of the propellant in model samples of the product

The degree of evacuation of the contents was determined for each sample.

The results of experiments for determination of the degree of evacuation of the contents are presented in Fig. 1.

Based on the data in Fig. 1, it can be concluded, that the maximum degree of evacuation is observed with sample 6 , whereas this parameter is practically the same for samples $8-10$.

The results of the test for determination of excess pressure in each sample aerosol packaging are presented in Fig. 2.

Starting from sample 6 the excess pressure in the package rises and remains practically the same till sample 9. As a whole, the increase in the degree of evacuation corresponds to the increase in excess pressure, except for samples 5, 7 and 10 .

Further mass fractions of a propellant were determined in each test sample.

The results of experiments for determination of mass fraction of a propellant in aerosol packaging are presented in Fig. 3. 


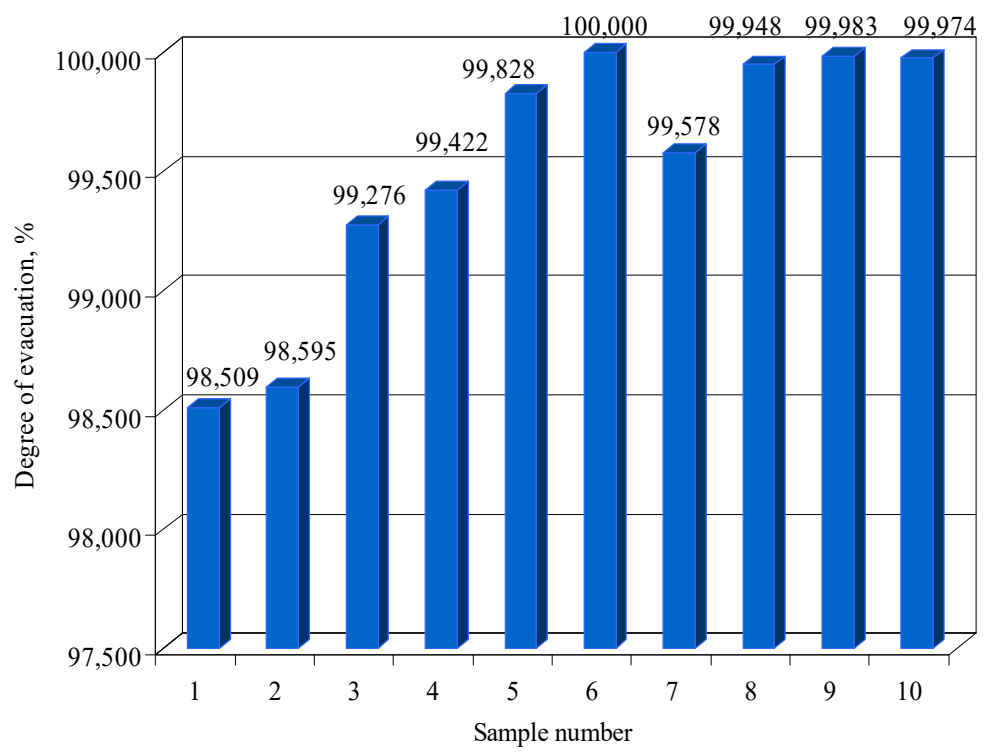

Fig. 1. Degree of evacuation of the contents from aerosol package

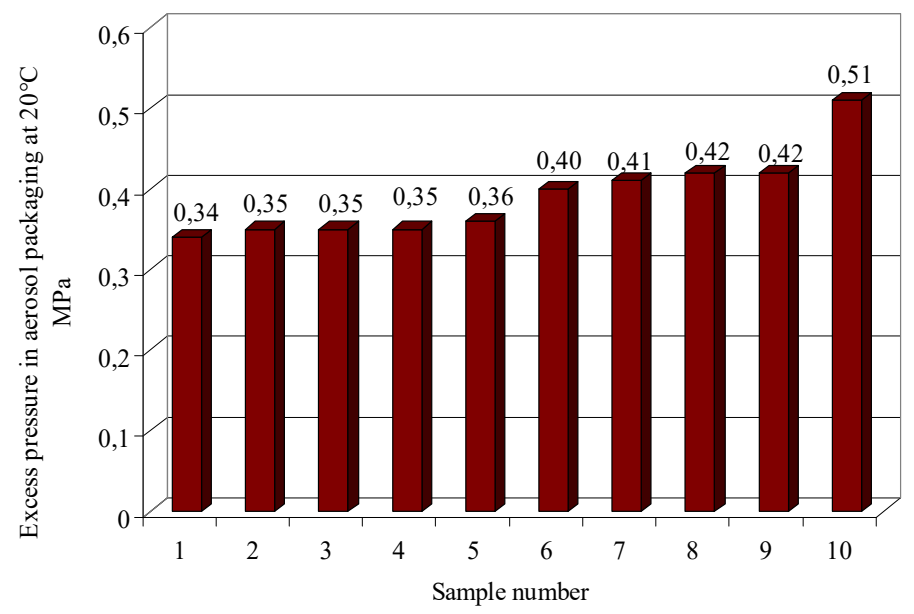

Fig. 2. Determination of excess pressure in aerosol package

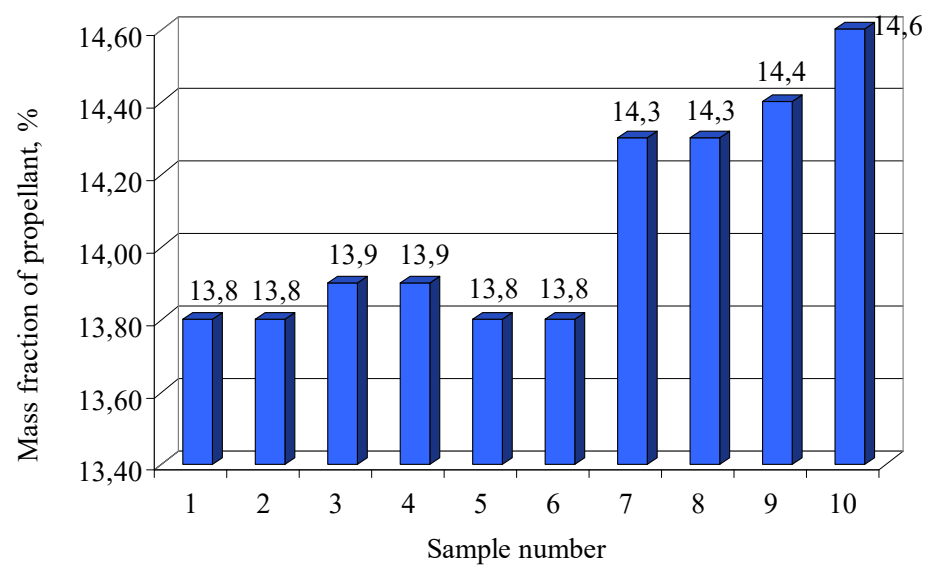

Fig. 3. Determination of mass fraction of a propellant in aerosol package

As follows from the data, presented in Fig. 3, the increase in mass fraction of a propellant is observed starting from sample 7. This section also correlates with the increase in the degree of evacuation and excess pressure. 
Therefore, the maximum degree of evacuation of the contents from aerosol package is observed for sample 6 , whereby the propellant pressure is $0.40 \mathrm{MPa}$, which falls within the acceptable limits, and the mass fraction of a propellant is $13.79 \%$.

\section{Discussion of results of determination of the degree of evacuation of the contents, excess pressure, mass fraction of a propellant in model samples of the product}

Based on the data, obtained from the test for degree of evacuation of the contents from aerosol packaging, determination of the excess pressure and mass fraction of a propellant in the cosmetic product GYDERLIFE-INTENSIVE, the following findings have been made. With the mass fraction of a propellant of $13.79 \%$ the product is evacuated from the bottle to the maximum extent. The propellant pressure is well within the acceptable limits. The results obtained allow estimating the correctness of selection of a good package for the cosmetic product "GYDERLIFEINTENSIVE" and the amount of a propellant in the composition of the product.

It should be noted, that with 1,1,2,2-tetrafluoroethane (Freon-134a), used as a propellant, the product obtains a number of required safety characteristics. Among them are: non-toxicity, non-flammability, ODP coefficient (ozone depletion potential) equalling to zero, which are required under the Technical regulations of the Customs Union TR CU 009/2011 "On safety of perfumery and cosmetics" .

It should also be noted, that methods for determination of parameters of the cosmetic product GYDERLIFE-INTENSIVE, which were included in the experimental part of this article, shall be further used as quality control methods for the finished product.

\section{Conclusion}

The greatest degree of evacuation of the product was observed for sample 6 and was $100 \%$. Following the tests for excess pressure in aerosol package, samples 6 and 7 showed the mean value according to the set limits $(0.2-0.6 \mathrm{MPa})$. During the determination of the mass fraction of propellant samples 5 and 6 showed the optimum value for the amount of a propellant in the test product. Summarizing all above mentioned information, it can be concluded, that parameters, chosen for sample 6, are optimum and acceptable. The optimum amount of a propellant is $13.79 \%$ with the excess pressure of $0.40 \mathrm{MPa}$. These parameters are the criteria for the effective use of this kind of packages.

The results of the experimental tests obtained in this work are of great importance for perfume and cosmetic industry, where products in aerosol packages are produced. In this case topical issues are quality and safety of products, ability of the products to preserve their physicochemical and organoleptic properties over a prolonged period of time. To solve these tasks special packages and substances are used, allowing preventing changes in the product. Thus, the critical issue is preservation of quality of products, containing essential oils, which change their structure under the influence of oxygen, moisture and other factors. For such products it is most practically to use aerosol package with addition of a propellant, which displaces air. Another critical issue is the degree of evacuation of the product from such package.

The value of the optimum mass fraction of a propellant, corresponding to the acceptable excess pressure will allow using this type of packaging more effectively and rationally.

The work determines the data for the cosmetic product GYDERLIFE-INTENSIVE, whereas there is a wide range of products in aerosol package, where peculiarities and the composition of the contents of the package are to be taken into account.

A perspective direction in this field is testing these parameters for various types of propellant gases, as well as products with various compositions and for various purposes.

\section{References}

[1] Regulation (EC) No 1223/2009 of the European Parliament and of the Council of 30 November 2009 on cosmetic products.

[2] TR TS 009/2011 Technical regulation of the Customs Union "On the safety of perfumes and cosmetics".

[3] Directives commission directive (EU) 2016/2037 of 21 November 2016 amending Council Directive 75/324/EEC as regards the maximum allowable pressure of aerosol dispensers and to adapt its labelling provisions to Regulation (EC) No 1272/2008 of 
the European Parliament and of the Council on classification, labelling and packaging of substances and mixtures (Text with EEA relevance), 3 .

[4] GOST 31677-2012. Aerosol packaged perfumery and cosmetic products. General specifications (2012).

[5] ISO 22715. Cosmetics-Packaging and labelling (2006).

[6] Putyatin, B. V. (2020). Zayavka na patent na poleznuyu model' No. u202002506. Kosmeticheskaya aerozol'naya kompozitsiya v forme spreya dlya kozhi «Gyderlife-Intensive».

[7] ISO 22716-2013. Perfume and cosmetic products. Good manufacturing practices (GMP). Guidelines on good manufacturing practices (2013).

[8] ISO 20072:2009. Aerosol drug delivery device design verification - Requirements and test methods (2009).

[9] Liapunov, M., Zahorii, V., Bezuhla, O. et. al. (2009). Nastanova ST N MOZU 42 4.0. Likarski zasoby. Nalezhna vyrobnycha praktyka. Kyiv, 212.

[10] Bitsch, A., Blume, A., Delmaar, C., Hahn, S., Heiland, A., Heinemeyer, G. et. al. (2019). Exposure to Substances by Use of Consumer Products. The Practice of Consumer Exposure Assessment, 361-479. doi: https://doi.org/10.1007/978-3-319-96148-4_5

\title{
PROBATION OF THE IMPROVED UNINTERRUPTED PASTEURIZATION SET "TUBE IN TUBE"
}

\author{
Andrii Zahorulko \\ Department of Processes, Devices and Automation of Food Production ${ }^{1}$ \\ zagorulkoAN@hduht.edu.ua \\ Aleksey Zagorulko \\ Department of Processes, Devices and Automation of Food Production ${ }^{1}$ \\ zagorulko@hduht.edu.ua \\ Maryna Yancheva \\ Department of Meat Technology ${ }^{1}$ \\ ya.marina11@gmail.com \\ Olena Dromenko \\ Department of Meat Technology ${ }^{1}$ \\ olena_dromenko@ukr.net \\ Mariana Sashnova \\ Department of Software Engineering and Cybersecurity \\ Kyiv National University of Trade and Economics \\ 19 Kyoto str., Kyiv, Ukraine, 02156 \\ m.sashnova@gmail.com \\ ${ }^{1}$ Kharkiv State University of Food Technology and Trade \\ 333 Klochkivska str., Kharkiv, Ukraine, 61051
}

\footnotetext{
Abstract

There have been conducted probation studies of an improved uninterrupted pasteurization set "tube in tube" that allowed to provide modern market needs of consumers in getting high-quality food products that must undergo pasteurization stages at technological production. Heat delivery by FFREHRT is used in the set for providing heat flow distribution evenness. There has been established the optimal working space of processed raw materials by studying a temperature drop in the middle of the raw material flow and at the apparatus surface. At the width of the linear ring size of the working environment as $9.5 \mathrm{~mm}$ and the flow speed as
} 